\title{
Efeito da substituição dos antimicrobianos pelo ovo desidratado na fase pré- inicial de frangas de dois grupos genéticos alojadas em camas nova e reciclada
}

\author{
José Humberto Vilar da Silva ${ }^{1}$, José Jordão Filho ${ }^{2}$, Edson Lindolfo da Silva ${ }^{3}$, Marcelo Luís \\ Gomes Ribeiro ${ }^{2,4}$, José Anchieta de Araújo ${ }^{5}$, Fernando Guilherme Perazzo Costa ${ }^{6}$
}

\author{
${ }^{1}$ DAP/CFT/UFPB, Bananeiras - PB e PPGZ/CCA/UFPB, Areia - PB. Bolsista CNPq-PQ. \\ 2 Doutorado Integrado em Zootecnia, CCA/UFPB/UFRPE/UFC, Areia - PB. \\ ${ }^{3}$ Doutorando em Zootecnia, PPGZ/DZO/UFLA, Lavras - MG. Bolsista do CNPq \\ ${ }^{4}$ Departamento de Agropecuária - CFT/UFPB - Campus III. Bananeiras-PB. \\ ${ }^{5}$ Graduação em Lic. em Ciências Agrárias - Bolsista PIBIC/UFPB/CNPq. \\ 6 PPGZ/DZ/CCA/UFPB, Areia - PB. Bolsista CNPq-PQ.
}

RESUMO - O efeito da substituição dos antimicrobianos (A) pelo ovo desidratado (OD) na ração e do tipo de cama (nova ou reciclada) usada na cobertura do piso sobre o desempenho de pintainhas de dois grupos genéticos foi avaliado em 1.440 aves de 1 dia de idade ( 720 de cada linhagem - leve e semipesada), distribuídas em 72 boxes de 1 x 1,5 m. A cama reciclada consistiu de bagaço de cana contaminado com excretas de frangos com sintomas de coccidiose. As pintainhas foram pesadas e distribuídas em um delineamento inteiramente ao acaso, em arranjo fatorial 3 x 2 × 2 (três rações x duas camas x duas linhagens), totalizando 12 tratamentos, cada um com seis repetições de 20 aves. As rações, formuladas com doses comerciais de antimicrobianos $\left(R_{1}\right)$, sem antimicrobianos $\left(R_{2}\right)$ ou sem antimicrobianos $+0,6 \%$ de OD $\left(R_{3}\right)$, foram fornecidas à vontade até os 7 dias de idade. $O$ ovo desidratado foi composto de gema e albúmem desidratados a $55^{\circ} \mathrm{C}$ durante 72 horas e apresentou resultado negativo para Salmonella spp. O uso da cama reciclada afetou o desempenho das pintainhas dos dois grupos genéticos, especialmente das semipesadas, que apresentaram também menores pesos de baço e da bolsa de Fabricius, sugerindo atrofia de tecidos linfóides, o que provavelmente explica a menor tolerância dessas aves ao ambiente com cama reciclada. Os antimicrobianos atenuaram o efeito redutor do ambiente com cama reciclada sobre o desempenho das aves. O fornecimento de ovo desidratado é uma boa alternativa aos antimicrobianos e pode melhorar o desempenho de aves na fase pré-inicial criadas em ambiente convencional.

Palavras-chave: desempenho, estresse, promotor de crescimento

\section{Effect of antimicrobial replacement with dehydrated egg in the pre-starter phase of two genetics groups of pullets allotted to new and recycled litters}

\begin{abstract}
The effect of antimicrobial (A) replacement with dehydrated egg (DE) and of type of litter (new and recycled) used in the floor covering on pullet performance was evaluated in 1,440 1-d chicks, 720 of each strain (White and Brown), allotted to 72 boxes ( $1 \times 1.5 \mathrm{~m}$ ). Recycled litter consisted of sugar cane bagasse containing droppings of broilers chicks with symptoms of coccidiose. The pullets were weighed and assigned to a complete randomized design with a $3 \times 2 \times 2$ (three diets $x$ two litter $x$ two strains) factorial arrangement, in a total of 12 treatments with six replications of 20 pullets. The experimental diets (D) were: $\mathrm{D}_{1}=$ diet with commercial dose of antimicrobial; $\mathrm{D}_{2}=$ diet without antimicrobial; and $\mathrm{D}_{3}=$ diet without antimicrobial $+0.6 \%$ of DE. DE was composed by dehydrated yolk+albumen $\left(55^{\circ} \mathrm{C}\right.$ for 72 hours $)$ and showed negative result to Samonella spp. test. The use of recycled litter decreased pullet performance of two genetic groups, specially the Brown ones, that showed lower weights of spleen and bursa of Fabricius. This fact suggests better enlargement of lymphoid tissues, and that probably explains the smaller tolerance of White pullets to recycled litter. The antimicrobials minimize negative effect of recycled litter on pullet performance. Dehydrated egg is a good alternative to antimicrobials and can improve performance of pullets in the pre-starter on conventional environment.
\end{abstract}

Key Words: antimicrobial drugs, environmental stress, performance

\section{Introdução}

A primeira semana de vida é um período de alto risco para a saúde e sobrevivência das aves, especialmente aquelas alimentadas sem antimicrobianos na ração e criadas em ambientes com cama reciclada. Segundo Stayer et al. (1995), citados por Stanley et al. (2004), o alto custo e a baixa disponibilidade de material têm forçado os avicultores 
a reciclar a cama das aves, uma condição de alojamento que pode agravar os problemas de infecções ocasionados por Eimerias spp.e bactérias nos plantéis de aves.

A interação ambiente $\times$ antibióticos $\times$ desempenho de pintos de corte foi estabelecida em trabalhos clássicos há mais de 40 anos (Levs \& Forbes, 1959; Coates et al., 1963). Os autores demonstraram que, em ambiente livre de patógenos, o ganho de peso das aves não é alterado pela presença ou ausência de antibiótico na ração. Mais tarde, Roura et al. (1992) confirmaram a informação de que, em ambientes sujos, o uso de antibióticos promove melhor desempenho.

As recentes pressões políticas e a preocupação dos consumidores com o uso dos antimicrobianos nas rações têm aumentado o interesse da indústria avícola na busca de alternativas aos antimicrobianos.

Os produtos testados para melhorar o desempenho das aves na ausência de antimicrobianos são as enzimas, os micróbios competitivos e a pré-colonização do trato gastrointestinal com microrganismos benéficos que inibem o ataque de patógenos à mucosa intestinal(Cook, 2004). Outras alternativas têm sido os ácidos orgânicos, os extratos vegetais, o extrato de própolis, os óleos essenciais, os subprodutos de origem animal, como o plasma sangüíneo e o ovo desidratado (composto por gema e albúmem dos ovos com má formação de casca, dos ovos quebrados ou rachados durante a coleta e embalagem nas granjas) e os resíduos da indústria do ovo líquido.

Quantidade substancial de subprodutos do ovo pode ser obtida no Brasil. Em 2003, a produção no país foi de 14,4 bilhões de unidades de ovo (Avicultura Industrial, 2003), com descarte médio de 3\% de ovos nas granjas por avarias na casca. Segundo Harmon et al. (2001), no setor de embalagem, são descartados $2 \%$ dos ovos após a ovoscopia e, de acordo com Schmidt et al. (2003), grande volume de subprodutos resulta da indústria do ovo líquido, tendo potencial econômico e nutricional para ser aproveitado na alimentação animal.

O ovo pode contribuir nutricional e profilaticamente para melhorar o desempenho das aves, pois, na fase pós-eclosão, o metabolismo energético de lipídios predomina sobre o dos carboidratos (Dibner, 1997). De acordo com Noy \& Sklan (1999), na fase pós-eclosão, o intestino fica repleto de gema, formando-se uma camada hidrofóbica sobre a borda em escova, o que aumenta o aproveitamento de moléculas hidrofóbicas como o ácido oléico e prejudica as hidrofílicas, como a glicose e metionina. Segundo Noy et al. (2001), esta camada resulta dos movimentos peristálticos e aumenta a entrada do resíduo da gema no intestino, fazendo com que chegue à moela. À eclosão, a absorção de gordura da gema (ácidos graxos de cadeia longa, mono e poliinsaturados) se torna, então, um processo muito mais eficiente.

Portanto, o subproduto do ovo pode ser usado na alimentação animal com duplo propósito: como fonte de nutrientes e como antibiótico não farmacêutico. $\mathrm{O}$ ovo desidratado possui $48 \%$ de PB, $29 \%$ de gordura e $4.278 \mathrm{kcal} / \mathrm{kg}$ de EMAn na matéria natural, sendo $25 \%$ mais energético que o milho e tão rico em proteína quanto o farelo de soja (Teixeira et al., 2005).

Um ovo contém, em média, $150 \mathrm{mg}$ de $\gamma$-globulina (Harmon et al., 2001) e albumina na clara, considerada proteína padrão pelo ótimo perfil de aminoácidos. O ovo também contém a lizosima, uma enzima que degrada a parede celular de bactérias, especialmente as gram-positivas, com ação limitada sobre asgram-negativas (Schimidt et al., 2003; Owusu-Asiedu et al., 2003a, b), e possui alto conteúdo de ácidos graxos poliinsaturados (Owusu-Asiedu et al., 2003ab), que atenuam as respostas inflamatórias em pintos (Persia et al., 2006). Anticorpos específicos (antiCCK e anti-fosfolipase $\mathrm{A}_{2}$ ) na gema podem atuar sobre processos envolvidos na regulação imune e no crescimento das aves (Cook, 2004).

As doenças co-existem com as aves no campo e, por isso, os programas de melhoramento visam desenvolver genótipos de aves resistentes, mas, para uma nova progênie chegar ao mercado, são necessários quatro anos e, face às rápidas mutações dos patógenos, essas aves podem chegar ao mercado e encontrar uma nova cepa de vírus, bactéria ou protozoário e contrair uma doença (Fultom, 2004). Aves saudáveis têm menor custo de produção, permitindo que os recursos economizados sejam alocados para o crescimento e a produção de ovos em vez de serem utilizados no combate de doenças (Erf \& Taylor, 2004).

O alojamento de pintainhas na primeira semana em cama reciclada é uma condição crítica para avaliar a resistência das linhagens comerciais e a eficácia nutricional e profilática do ovo desidratado na ausência de antimicrobianos na ração. Neste trabalho, avaliou-se o efeito do ovo desidratado na ração pré-inicial de pintainhas de dois grupos genéticos alojadas em condições convencionais e de alto desafio microbiano.

\section{Material e Métodos}

O experimento foi realizado no aviário do Campus de Bananeiras, da Universidade Federal da Paraíba, em janeiro de 2004.

Um plantel de 1.440 aves - 720 leves (PL) e 720 semipesadas (PSP) - com 1 dia de idade, não-vacinadas 
contra coccidiose, foi pesado e distribuído aleatoriamente em 72 boxes de $1 \times 1,5 \mathrm{~m}$.

O galpão foi dividido por um cortinado em duas áreas: limpa e suja. No ambiente limpo ou convencional, o piso foi coberto com cama nova e, na área suja, cama reciclada. O material reciclado foi obtido de um galpão on de os frangos de corte apresentaram baixo crescimento, fezes com tonalidades marrons e presença de sangue no conteúdo cecal, sintomas típicos da coccidiose causada por Eimeria tenella.

O ambiente limpo foi localizado na posição de recebimento dos ventos dominantes e foi pulverizado com solução desinfetante três vezes ao dia para manter baixo nível de contaminação. O manejo diário das aves foi iniciado pelo ambiente limpo, seguido daquele com cama reciclada.

$\mathrm{O}$ experimento foi desenvolvido em um delineamento inteiramente ao acaso, em arranjo fatorial $3 \times 2 \times 2$ (três rações $\mathrm{x}$ dois ambientes $\mathrm{x}$ duas linhagens), resultando em 12 tratamentos com seis repetições de 20 aves. As rações, isonutritivas (Tabela 1), foram formuladas segundo Rostagno et al. (2000). Na ração 1, os antimicrobianos Coban-500 (monensina sódica) e bacitracina de zinco foram incluídos em doses comerciais $(0,05$ e $0,015 \%$, respectivamente) e retirados nas rações 2 e 3 , a última suplementada com $0,6 \%$ de ovo desidratado (OD).

No preparo do ovo desidratado, foram utilizados albúmem e gema de ovos com casca avariada (mole, trincada e quebrada) ou com manchas de sangue na casca, obtidos de uma granja comercial. O conteúdo fresco do ovo foi pesado, colocado em bandejas de metal e seco em estufa de circulação forçada a $55^{\circ} \mathrm{C}$, durante 72 horas. O rendimento do produto seco em relação ao produto in natura foi de $24,6 \%$ e, na análise de sua composição química, obteve-se o seguinte resultado: $94,22 \%$ de MS, $47,79 \%$ de PB e $29,04 \%$ de gordura bruta.

O material desidratado foi acondicionado em sacos plásticos e armazenado em freezer a $-8^{\circ} \mathrm{C}$. O uso do produto na ração foi precedido do teste para detecção de Salmonella spp., no qual foi obtido resultado negativo. Como composição em aminoácidos, minerais e vitaminas do OD, foram considerados os valores descritos por Staldemann et al. (1995) e, como valores de EMAn e proteína, foram estabelecidos aqueles citados por Teixeira et al. (2005).

O processo de secagem do ovo em baixa temperatura, porém com longo tempo de exposição, foi realizado para eliminar patógenos como Salmonellas, inativar o ovomucóide, que tem atividade de inibir a tripsina, e minimizar a formação da reação de Maillard, que reduz a digestibilidade dos aminoácidos, e a inativação de
Tabela 1 - Composição química das rações experimentais Table 1 - Chemical composition of the experimental diets

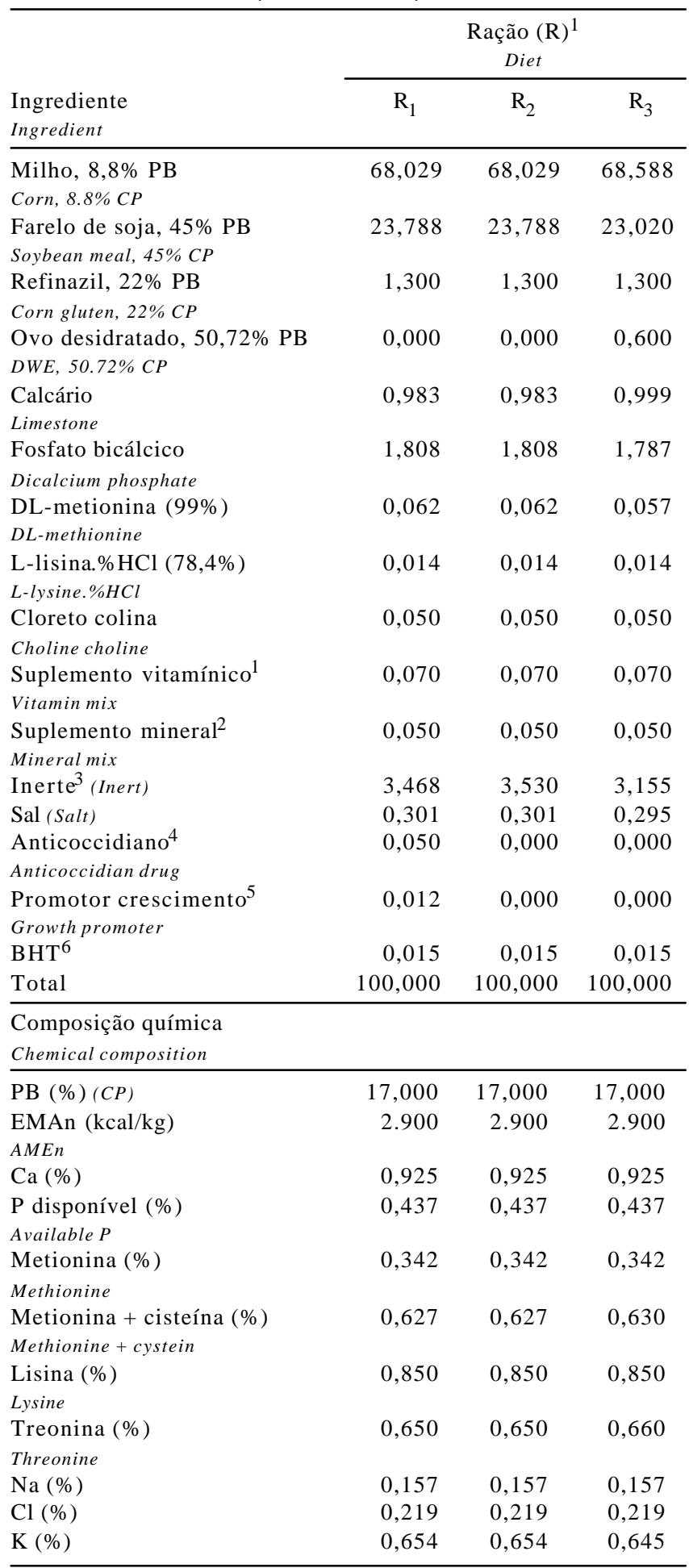

1 Suplemento vitamínico (vitamin premix) - $\mathrm{kg}$ do produto ( $\mathrm{kg}$ of product): vit. A - 40.000.000 UI; vit. D3 - 8.000.000 UI; vit. E, 100.000 UI; vit. $K_{3}-6.000,0 \mathrm{mg}$; vit. $B_{1}-6.000,0 \mathrm{mg}$; vit. $B_{2}-20.000,0 \mathrm{mg}$; vit. $\mathrm{B}_{6}$ - 12.000,0 mg; vit. $B_{12}-60.000,0 \mathrm{mg}$; biotina (biotin) - 320,0 mg; ácido fólico (folic acid) - $2.800 \mathrm{mg}$; ácido nicotínico (nicotinic acid) - 120.000,0 mg; ácido pantotênico (pantothenic acid) - 40.000,0 mg; Se - 1.000,0 mg.

2 Suplemento mineral (Mineral premix): $\mathrm{kg}$ do produto ( $\mathrm{kg}$ of product): $\mathrm{Mn}-150.000 \mathrm{mg} ; \mathrm{Zn}-100.000 \mathrm{mg} ; \mathrm{Fe}-100.000 \mathrm{mg}$; Cu, $16.000 \mathrm{mg}$ e I, $1.500 \mathrm{mg}$.

${ }^{3}$ Areia de construção lavada (Builder washed sand).

4 Coban 500 (monesina sódica).

5 Bacitracina de zinco.

${ }^{6}$ BHT(Butil-hidroxi-tolueno), galato de propila, cabonato de cálcio (calcium carbonate). Níveis de garantia do produto (Guaranty levels)- BHT $100 \mathrm{~g} / \mathrm{kg}$. 
imunoglobulinas e lisozima. A temperatura foi inferior à utilizada por Schimidt et al. (2003) no armazenamento do ovo desidratado a $70^{\circ} \mathrm{C}$ durante três dias. Segundo esses autores, o tratamento térmico acentua a atividade antimicrobiana da lisozima contra bactérias gram-negativas.

Aos 7 dias de idade, foram avaliados o peso final (PF), o consumo de ração (CR), o ganho de peso (GP) e a conversão alimentar (CA). Em seguida, foi abatida uma ave de cada parcela do ambiente com cama reciclada para necropsia do intestino e pesagem do baço e da bolsa de Fabricius. Para avaliação do grau e do local da infecção, foram coletadas amostras do conteúdo intestinal, as quais foram observadas quanto à coloração.

Os dados de desempenho foram avaliados por meio do programa SAEG (Euclydes, 1983). Nos contrastes que envolveram duas médias, considerou-se o resultado do teste $\mathrm{F}$ como conclusivo $(\mathrm{P} \leq 0,05)$ e, naqueles contrastes com três médias, utilizou-se o teste $\mathrm{SNK}(\mathrm{P} \leq 0,05)$ para comparação múltipla das médias.

\section{Resultados e Discussão}

As pintainhas criadas em cama reciclada apresentaram falta de apetite, sonolência, imobilidade e penas arrepiadas. As aves agrupavam-se como se estivessem com frio, sendo observados sintomas clássicos de coccidiose, como descrito por Calnek et al. (1991). Aos 7 dias, procedeu-se à necropsia apenas das aves alojadas na cama reciclada, constatando-se presença de sangue no conteúdo cecal. Ao final do experimento, efetuou-se a remoção imediata das aves para um galpão com cama nova e aplicou-se quimioterapia específica para combate à coccidiose e rápida recuperação do plantel.

Não houve efeito da interação tripla tipo de cama $\times$ linhagem das frangas $\times$ rações experimentais sobre nenhuma característica de desempenho estudada $(\mathrm{P}>0,05)$. Verificou-se, no entanto, efeito da interação simples ração $\times$ tipo de cama sobre o peso final, o ganho de peso $(\mathrm{P} \leq 0,01)$ e a conversão alimentar $(\mathrm{P} \leq 0,05)$, conforme ilustrado na Tabela 2. Também houve influência da interação $(\mathrm{P} \leq 0,01)$ tipo de cama $\times$ linhagem das pintainhas sobre $\mathrm{o}$ peso final, o ganho de peso, o consumo de ração e a conversão alimentar. A taxa de mortalidade, por sua vez, foi afetada apenas pela linhagem da ave $(\mathrm{P} \leq 0,05)$.

Considerando apenas os fatores principais, nota-se que o peso final, o consumo de ração, o ganho de peso e a conversão alimentar foram afetados pelo tipo de cama utilizada $(\mathrm{P} \leq 0,05)$, observando-se os piores resultados no ambiente com cama reciclada (Tabela 3). Esses resultados corroboram os registrados por outros autores (Coates et al., 1963; Roura et al., 1992), em estudos com frangos de corte alojados em ambientes limpo e sujo.

A linhagem semipesada, em comparação à leve, apresentou baixo consumo de ração e pior conversão alimentar $(\mathrm{P} \leq 0,05)$.

A mortalidade foi significativamente afetada pela linhagem da ave $(\mathrm{P} \leq 0,05)$, sendo registrada menor taxa de mortalidade para as pintainhas leves que para as semipesadas $(0,28$ vs $1,39 \%)$. Percentualmente, foram constatados menos óbitos entre as aves criadas em ambiente limpo que entre aquelas do ambiente com cama reciclada (0,56 vs. 1,11\%). Segundo Bar-Shira et al. (2003), as principais vias de contaminação das aves são as membranas dos tratos digestório, respiratório e genital. Portanto, a interação genótipo $\times$ ambiente é, provavelmente, fator crítico para a sobrevivência das aves na fase pré-inicial.

$\mathrm{Na}$ Tabela 4 são apresentados os resultados da interação simples tipo de cama $\times$ rações experimentais. Considerando apenas as rações, observa-se que as aves do ambiente com cama nova tiveram peso final, ganho de peso e conversão

Tabela 2 - Resultado da análise de variância para o peso final (PF), o ganho de peso (GP), o consumo total de ração (CTR), o consumo diário de ração (CDR), a conversão alimentar (CA) e a taxa de mortalidade (M), de acordo com os tratamentos

Table 2 - Result of analysis of variance for final weight (FW), weight gain (WG) total feed intake (TFI), dairy feed intake (DFI), feed conversion (FC) and mortality (M) according to the treatments

\begin{tabular}{|c|c|c|c|c|c|c|}
\hline $\begin{array}{l}\text { Tratamento } \\
\text { Treatment }\end{array}$ & $\begin{array}{l}\mathrm{PF}(\mathrm{g}) \\
\quad F W\end{array}$ & $\begin{array}{c}\text { GP (g/a) } \\
W G\end{array}$ & $\begin{array}{c}\mathrm{CTR}(\mathrm{g} / \mathrm{a}) \\
T F I\end{array}$ & $\begin{array}{c}\mathrm{CDR}(\mathrm{g} / \mathrm{a} / \mathrm{d}) \\
D F I\end{array}$ & $\begin{array}{c}\mathrm{CA}(\mathrm{kg} / \mathrm{kg}) \\
F C\end{array}$ & $\begin{array}{c}\mathrm{M}(\%) \\
\text { Mortality }\end{array}$ \\
\hline Ração (R) (Diet) & ns & $\mathrm{ns}$ & $\mathrm{ns}$ & $\mathrm{ns}$ & ns & $\mathrm{ns}$ \\
\hline Tipo de cama (C) (Litter type) & $* * *$ & $* * *$ & $* * *$ & $* * *$ & $* * *$ & ns \\
\hline Linhagem $(\mathrm{L})$ (Bird strain) & $* * *$ & $* * *$ & $* * *$ & $* * *$ & $*$ & $*$ \\
\hline $\mathrm{R} \times \mathrm{C}$ & $* * *$ & $* * *$ & ns & ns & $*$ & ns \\
\hline $\mathrm{R} \times \mathrm{L}$ & $\mathrm{ns}$ & ns & $\mathrm{ns}$ & ns & ns & ns \\
\hline $\mathrm{C} \times \mathrm{L}$ & $* * *$ & $* * *$ & $* * *$ & $* * *$ & $* * *$ & $\mathrm{~ns}$ \\
\hline $\mathrm{R} \times \mathrm{C} \times \mathrm{L}$ & ns & $\mathrm{ns}$ & ns & $\mathrm{ns}$ & $\mathrm{ns}$ & ns \\
\hline $\mathrm{CV}(\%)$ & 5,27 & 7,25 & 6,49 & 6,49 & 8,29 & 12,29 \\
\hline
\end{tabular}

${ }^{*} \mathrm{P} \leq 0,05 ;{ }^{*} \mathrm{P} \leq 0,01 ;{ }^{* * *} \mathrm{P}<0,001$

ns $=$ não-significativo $(P>0,05)($ Not significant, $P>0.05)$. 
Tabela 3 - Peso vivo (PV), consumo total de ração (CTR), consumo diário de ração (CDR), ganho de peso (GP), mortalidade (M) e conversão alimentar (CA) de frangas leves e semipesadas na primeira semana, de acordo com o tipo de ração e a cama utilizada

Table 3 - Body weight (BW), total feed intake (TFI), daily feed intake (DFI), weight gain (WG), mortality (M) and feed conversion (FC) of Lohmann White $(L W)$ and $L$. Brown (LB) pullets during first week according to the diet and litter type

\begin{tabular}{|c|c|c|c|c|c|c|}
\hline $\begin{array}{l}\text { Tipo de cama } \\
\text { Litter type }\end{array}$ & $\begin{array}{c}\mathrm{PV}(\mathrm{g}) \\
B W\end{array}$ & $\begin{array}{c}\text { CRT }(\mathrm{g}) \\
\text { TFI }\end{array}$ & $\begin{array}{c}\mathrm{CRD}(\mathrm{g} / \mathrm{d}) \\
D F I\end{array}$ & $\begin{array}{c}\mathrm{GP}(\mathrm{g}) \\
W G\end{array}$ & $\mathrm{M}(\%)$ & $\begin{array}{c}\mathrm{CA}(\mathrm{kg} / \mathrm{kg}) \\
M F C\end{array}$ \\
\hline $\begin{array}{l}\text { Nova (New) } \\
\text { Reciclada (Recycled) }\end{array}$ & $\begin{array}{l}71,88^{\mathrm{A}} \\
54,20^{\mathrm{B}}\end{array}$ & $\begin{array}{l}75,31^{\mathrm{A}} \\
57,13^{\mathrm{B}}\end{array}$ & $\begin{array}{c}10,76^{\mathrm{A}} \\
8,16^{\mathrm{B}}\end{array}$ & $\begin{array}{l}37,08^{\mathrm{A}} \\
19,27^{\mathrm{B}}\end{array}$ & $\begin{array}{l}0,56 \\
1,11\end{array}$ & $\begin{array}{l}2,031^{\mathrm{A}} \\
2,965^{\mathrm{B}}\end{array}$ \\
\hline \multicolumn{7}{|l|}{ Linhagem (Bird strain) } \\
\hline $\begin{array}{l}\text { Leve (White) } \\
\text { Semipesada (Brown) }\end{array}$ & $\begin{array}{l}68,40^{\mathrm{A}} \\
57,64^{\mathrm{B}}\end{array}$ & $\begin{array}{l}78,78^{\mathrm{A}} \\
53,67^{\mathrm{B}}\end{array}$ & $\begin{array}{c}11,25^{\mathrm{A}} \\
7,067^{\mathrm{B}}\end{array}$ & $\begin{array}{l}31,96^{\mathrm{A}} \\
24,39^{\mathrm{B}}\end{array}$ & $\begin{array}{l}0,28^{\mathrm{A}} \\
1,39^{\mathrm{B}}\end{array}$ & $\begin{array}{l}2,465^{\mathrm{B}} \\
2,200^{\mathrm{A}}\end{array}$ \\
\hline $\mathrm{R}_{1}=+\operatorname{ANTIM}_{(+ \text {ANTIM })}$ & 63,54 & 67,18 & 9,60 & 29,10 & 0,83 & 2,308 \\
\hline $\mathrm{R}_{2}=-\operatorname{ANTIM}_{(-A N T I M)}$ & 63,06 & 66,46 & 9,49 & 27,91 & 0,83 & 2,381 \\
\hline $\mathrm{R}_{3}^{2}=-\mathrm{ANTIM}+\mathrm{OD}(-A N T I M+D E)$ & 62,52 & 65,04 & 9,29 & 27,53 & 0,83 & 2,362 \\
\hline
\end{tabular}

1 ANTIM = antimicrobianos; OD = ovo desidratado (ANTIM =antimicrobial; DE = dehydrated egg).

$A B$ Médias na coluna seguidas de letras maiúsculas distintas são diferentes $(P \leq 0,05)$ pelo teste $F$.

${ }_{A B}^{A B}$ Means within a colunm, without an uncommon superscript letter differ $(P \leq 0.05)$ by $F$ test.

Tabela 4 - Efeito da ração e do tipo de cama sobre o desempenho de pintainhas na fase pré-inicial Table 4 - Effect of diet and litter type on performance of pullets in the pre-starter phase

\begin{tabular}{|c|c|c|c|c|c|c|}
\hline \multirow[t]{2}{*}{$\begin{array}{l}\text { Ração (R) } \\
\text { Diet }\end{array}$} & \multicolumn{2}{|c|}{$\begin{array}{l}\text { Peso viso }(\mathrm{g}) \\
\text { Body weight }\end{array}$} & \multicolumn{2}{|c|}{$\begin{array}{l}\text { Ganho de peso }(\mathrm{g}) \\
\text { Weight gain }\end{array}$} & \multicolumn{2}{|c|}{$\begin{array}{c}\text { Conversão alimentar }(\mathrm{kg} / \mathrm{kg}) \\
\text { Feed conversion rate }\end{array}$} \\
\hline & $\begin{array}{l}\text { Cama nova } \\
\text { New litter }\end{array}$ & $\begin{array}{l}\text { Cama reciclada } \\
\text { Recycled litter }\end{array}$ & $\begin{array}{l}\text { Cama nova } \\
\text { New litter }\end{array}$ & $\begin{array}{l}\text { Cama reciclada } \\
\text { Recycled litter }\end{array}$ & $\begin{array}{l}\text { Cama nova } \\
\text { New litter }\end{array}$ & $\begin{array}{c}\text { Cama reciclada } \\
\text { Recycled litter }\end{array}$ \\
\hline $\begin{array}{l}\mathrm{R}_{1} \\
\mathrm{R}_{2} \\
\mathrm{R}_{3}\end{array}$ & $\begin{array}{l}70,36^{\mathrm{a}} \\
71,76^{\mathrm{a}} \\
73,52^{\mathrm{a}}\end{array}$ & $\begin{array}{c}56,73^{\mathrm{bA}} \\
54,35^{\mathrm{bAB}} \\
51,52^{\mathrm{bB}}\end{array}$ & $\begin{array}{l}35,95^{\mathrm{a}} \\
36,80^{\mathrm{a}} \\
38,50^{\mathrm{a}}\end{array}$ & $\begin{array}{c}22,24^{\mathrm{bA}} \\
19,02^{\mathrm{bAB}} \\
16,56^{\mathrm{bAB}}\end{array}$ & $\begin{array}{l}2,072^{\mathrm{b}} \\
2,050^{\mathrm{b}} \\
1,994^{\mathrm{b}}\end{array}$ & $\begin{array}{l}2,905^{\mathrm{aB}} \\
3,563^{\mathrm{aA}} \\
3,571^{\mathrm{aA}}\end{array}$ \\
\hline
\end{tabular}

ab Médias na linha seguidas de letras minúsculas distintas são diferentes pelo teste $\mathrm{F}$ a $5 \%$ de probabilidade.

AB Médias nas colunas seguidas de letras maiúsculas distintas são diferentes pelo teste SNK a $5 \%$ de probabilidade.

$1 \mathrm{R} 1$ = ração convencional; $\mathrm{R} 2$ = ração sem antimicrobianos; R3 = ração sem antimicrobianos + ovo desidratado.

ab Means within a row, without an uncommon subscript letter differ $\left(P_{\leq} 0.05\right)$ by $F$ test.

$A B$ Means within collunm, without uncommom superscript letter differ ( $\left.P_{\leq} 0.05\right)$ by SNK test.

$1 D 1=$ conventional diet; $D 2=$ diet without antimicrobial agents; $D 3=$ diet without antimicrobial agents with dehydrated eggs.

alimentar melhores $(\mathrm{P} \leq 0,05)$ que aquelas criadas no ambiente com cama reciclada.

Quando considerado apenas o ambiente com cama nova, não houve efeito significativo das rações $(\mathrm{P}>0,05)-$ apenas melhora de $4,3 \%$ no peso final, de $6,6 \%$ no ganho de peso e de $3,8 \%$ na conversão alimentar com a adição de $0,6 \%$ de OD em comparação à ração convencional. Esse resultado sugere que o uso de ovo desidratado pode melhorar o desempenho de aves criadas em ambiente convencional, o que está de acordo com o estudo de Schmidt et al. (2003), que notaram potencial do ovo em pó desidratado pelo processo spray dried em melhorar o desempenho de leitões na fase pré-inicial.

Ao contrário da tendência verificada no ambiente com cama nova, no ambiente com cama reciclada, inexplicavelmente, o menor peso vivo foi observado nas aves alimentadas com ração sem antimicrobianos $+0,6 \%$
$\mathrm{OD}\left(\mathrm{R}_{3}\right)$ e a pior conversão alimentar naquelas que receberam rações sem antimicrobianos $\left(\mathrm{R}_{2}\right.$ e $\left.\mathrm{R}_{3}\right)$, em comparação às do tratamento controle $\left(\mathrm{R}_{1}\right)$, contendo antimicrobianos $(\mathrm{P}<0,05)$. Provavelmente, a presença do ovo desidratado na ração agravou a infecção causada por Eimerias spp. De modo contrário, Stanley et al. (2004) observaram melhor ganho de peso em pintos de corte (1 a 42 dias) com a substituição do antibiótico ou anticoccidiano pela levedura de cerveja.

Como tratamento coadjuvante da coccidiose, Harms et al. (1967) recomendaram o aumento da densidade de nutrientes da dieta para compensar a redução do crescimento causada por esta doença.

Esta sugestão tem sido contrariada em alguns estudos, como o de Willis \& Baker (1981), que, avaliando o efeito da infecção induzida por níveis crescentes de oocistos de Eimeria acervulina, concluíram que o 
fornecimento de rações deficientes em aminoácidos sulfurosos e lisina resultou em maior eficiência alimentar em pintos contaminados. Quando os autores forneceram excesso desses aminoácidos na ração, os pintos infectados apresentaram menor eficiência. Entretanto, os autores não souberam explicar os motivos desse resultado.

Schutte et al. (1993) demonstraram maior presença de aminas biogênicas no trato digestivo de frangos alimentados com ração sem antimicrobianos e com alto conteúdo de proteína de baixa digestibilidade. Elwinger et al. (1994) comprovaram que, aumentando o nível dietético de proteína, o crescimento de Clostridium perfringens no ceco de frangos foi estimulado.O fornecimento de proteína fermentescível no intestino grosso a frangos e suínos resulta na formação de aminas biogênicas, amônia, componentes fenólicos e voláteis contendo enxofre na parte distal do intestino, comprometendo a saúde e o desempenho produtivo desses animais (Anderson et al., 2000). Existe ainda um custo energético associado à excreção urinária de compostos nitrogenados absorvíveis após a fermentação da proteína no intestino grosso (Birkett \& De Lange, 2001) que não deve ser menosprezado.

Considerando a interação simples tipo de cama $\times$ linhagem das pintainhas, as aves leves apresentaram, tanto no ambiente com cama nova quanto naquele com cama reciclada, melhor peso final e consumo de ração $(\mathrm{P} \leq 0,05)$ em comparação às semipesadas (Tabela 5). O peso vivo e o consumo de ração das duas linhagens também reduziram no ambiente de cama reciclada. Segundo Van Der Waaij et al. (2000), sob alta pressão de infecção combinada com baixo nível de resistência da ave, o desempenho animal pode desacelerar ou mesmo ser nulo.

Observou-se redução no ganho de peso das duas linhagens no ambiente com cama reciclada em comparação aos resultados obtidos no ambiente com cama nova (Tabela 6), contudo, apenas as pintainhas semipesadas apresentaram pior conversão alimentar no ambiente de cama reciclada em comparação ao ambiente com cama nova $(\mathrm{P} \leq 0,05)$.
No ambiente com cama nova, o ganho de peso e a conversão alimentar das duas linhagens não foram afetados $(\mathrm{P}>0,05)$, todavia, no ambiente com cama reciclada, os resultados destas duas características pioraram na linhagem semipesada $(\mathrm{P} \leq 0,05)$.

Como pode ser observado na Tabela 7, as rações não afetaram os pesos do baço e da bolsa de Fabricius das pintainhas alojadas no ambiente com cama reciclada, mas os pesos desses órgãos nas pintainhas leves foram maiores que nas semipesadas. Na linhagem semipesada, observou-se maior número de óbitos (Tabela 3 ) e de aves com sintomas de tristeza, sonolência e baixo crescimento.

A primeira semana é um período crítico para a sobrevivência das aves por várias razões, entre elas, a imunodepressão. Os maiores pesos da bolsa de Fabricius e do baço nas pintainhas leves destacam-se pelo fato de que essas aves têm maior tolerância às condições de ambiente com cama reciclada em comparação às pintainhas semipesadas. Portanto, o melhor desenvolvimento desses órgãos linfóides pode explicar parte desse resultado. Lillehoj et al. (2004) comprovaram aumento do RNAmao transcreverem para a interleucina -2 (IL-2) no baço de aves infectadas com E. acervulina. Portanto, o baço é um tecido linfóide de reação importante nas infecções causadas pela coccidiose.

Davison (2005), citando Murphy (1916), descreveu aumento do baço (esplenomegalia) em embriões de 7 dias que receberam transplante de fragmentos do baço de aves adultas pelo córion-alantóide. Os menores pesos do baço e da bolsa de Fabricius indicam maior sensibilidade da linhagem semipesada aos patógenos ambientais.

Segundo Guyton \& Hall (1997), a importância da bolsa de Fabricius e do baço no sistema imune decorre do fato de as células-tronco dos linfócitos B migrarem da membrana do saco da gema para serem pré-processadas na bolsa de Fabricius e, posteriormente, chegarem ao baço, ondesão clonadas e passam a atuar na defesa humoral, como sentinelas do organismo contra antígenos específicos.

Tabela 5 - Influência da interação linhagem $\times$ tipo de cama sobre o peso vivo e o consumo de ração de pintainhas na fase pré-inicial Table 5 - Effect of pullet strain $\times$ litter type on body weight and feed intake of pullets in the pre-starter phase

\begin{tabular}{|c|c|c|c|c|}
\hline \multirow[t]{2}{*}{$\begin{array}{l}\text { Linhagem } \\
\text { Strain }\end{array}$} & \multicolumn{2}{|c|}{$\begin{array}{l}\text { Peso viso }(\mathrm{g}) \\
\text { Body weight }\end{array}$} & \multicolumn{2}{|c|}{$\begin{array}{c}\text { Consumo de ração } \\
\text { Feed intake }\end{array}$} \\
\hline & $\begin{array}{l}\text { Cama nova } \\
\text { New litter }\end{array}$ & $\begin{array}{l}\text { Cama reciclada } \\
\text { Recycled litter }\end{array}$ & $\begin{array}{l}\text { Cama nova } \\
\text { New litter }\end{array}$ & $\begin{array}{l}\text { Cama reciclada } \\
\text { Recycled litter }\end{array}$ \\
\hline Leve (White) & $73,52^{\mathrm{aA}}$ & $63,29^{\mathrm{bA}}$ & $83,19^{\mathrm{aA}}$ & $74,37^{\mathrm{bA}}$ \\
\hline Semipesada (Brown) & $70,24^{\mathrm{aB}}$ & $45,12^{\mathrm{bB}}$ & $67,44^{\mathrm{aB}}$ & $39,90^{\mathrm{bB}}$ \\
\hline
\end{tabular}

ab Médias na linha seguidas de letras minúsculas distintas são diferentes pelo teste $\mathrm{F}$ a $5 \%$ de probabilidade.

AB Médias nas colunas seguidas de letras maiúsculas distintas são diferentes pelo teste $\mathrm{F}$ a $5 \%$ de probabilidade.

ab Means within a row, without an uncommon subscript letter differ $(P \leq 0.05)$ by $F$ test.

$A B$ Means within collunm, without uncommom superscript letter differ $\left(P_{\leq} 0.05\right)$ by $F$ test. 
Tabela 6 - Influência da interação linhagem × tipo de cama sobre o ganho de peso e a conversão alimentar de pintainhas na fase préinicial

Table 6 - Effect of pullet strain $\times$ litter type interaction on weight gain and feed conversion of pullets in the pre-starter phase

\begin{tabular}{|c|c|c|c|c|}
\hline \multirow[t]{2}{*}{$\begin{array}{l}\text { Linhagem } \\
\text { Bird strain }\end{array}$} & \multicolumn{2}{|c|}{$\begin{array}{l}\text { Ganho de peso } \\
\text { Weight gain }\end{array}$} & \multicolumn{2}{|c|}{$\begin{array}{c}\text { Conversão alimentar } \\
\text { Feed conversion }\end{array}$} \\
\hline & $\begin{array}{l}\text { Cama nova } \\
\text { New litter }\end{array}$ & $\begin{array}{l}\text { Cama reciclada } \\
\text { Recycled litter }\end{array}$ & $\begin{array}{l}\text { Cama nova } \\
\text { New litter }\end{array}$ & $\begin{array}{c}\text { Cama reciclada } \\
\text { Recycled litter }\end{array}$ \\
\hline Leve (White) & $37,25^{\mathrm{a}}$ & $26,68^{\mathrm{bA}}$ & $2,244^{\mathrm{bA}}$ & $2,844^{\mathrm{bB}}$ \\
\hline Semipesada (Brown) & $36,92^{\mathrm{a}}$ & $11,86^{\mathrm{bB}}$ & $1,833^{\mathrm{bA}}$ & $3,848^{\mathrm{aA}}$ \\
\hline
\end{tabular}

ab Médias na linha seguidas de letras minúsculas distintas são diferentes pelo teste $\mathrm{F}$ a $5 \%$ de probabilidade.

AB Médias nas colunas seguidas de letras maiúsculas distintas são diferentes pelo teste $\mathrm{F}$ a $5 \%$ de probabilidade.

ab Means within a row, without an uncommon subscript letter differ $\left(P_{\leq} 0.05\right)$ by $F$ test.

$A B$ Means within collunm, without uncommom superscript letter differ $(P \leq 0.05)$ by $F$ test.

Tabela 7 - Pesos do baço e da bolsa de Fabricius de frangas alojadas em ambiente com cama reciclada

Table 7 - Weights of spleen (SW) and bursa of Fabricius (BFW) of pullets on environment with recycled litter

\begin{tabular}{|c|c|c|}
\hline $\begin{array}{l}\text { Ração }(\mathrm{R})^{1} \\
\text { Diet }\end{array}$ & $\begin{array}{c}\text { Baço }(\mathrm{g}) \\
\text { Spleen weight }\end{array}$ & $\begin{array}{r}\text { Bolsa de Fabricius (g) } \\
\text { Bursa of Fabricius }\end{array}$ \\
\hline $\mathrm{R} 1(D 1)$ & 0,065 & 0,125 \\
\hline $\mathrm{R} 2(D 2)$ & 0,055 & 0,141 \\
\hline $\mathrm{R} 3$ (D3) & 0,062 & 0,118 \\
\hline \multicolumn{3}{|c|}{$\overline{\text { Linhagem }}{ }^{2}$ (Bird strain) } \\
\hline Leve (White) & $0,095^{\mathrm{A}}$ & $0,161^{\mathrm{A}}$ \\
\hline Semipesada (Brown) & $0,026^{\mathrm{B}}$ & $0,090^{\mathrm{B}}$ \\
\hline $\mathrm{CV}(\%)$ & 20,89 & 17,64 \\
\hline \multicolumn{3}{|c|}{$\begin{array}{l}\text { AB Médias na coluna seguidas de letras maiúsculas distintas são diferentes } \\
\text { pelo teste } \mathrm{F} \text { a } 5 \% \text { de probabilidade. }\end{array}$} \\
\hline \multicolumn{3}{|c|}{$\begin{array}{l}1 \mathrm{R} 1 \text { = ração convencional; } \mathrm{R} 2=\text { ração sem antimicrobianos; } \mathrm{R} 2 \text { = ração } \\
\text { sem antimicrobianos + ovo desidratado. }\end{array}$} \\
\hline \multicolumn{3}{|c|}{$\begin{array}{l}\text { Sem antimicrobianos + ovo desidratado. } \\
\text { Means within a collunm without uncommom superscript letter differ ( } P \leq 0.05) \text { by } F \text { test. }\end{array}$} \\
\hline \multicolumn{3}{|c|}{$\begin{array}{l}1 D 1=\text { conventional diet; } D 2=\text { diet without antimicrobial agents; } D 3=\text { diet without } \\
\text { antimicrobial agents with dehydrated egas }\end{array}$} \\
\hline
\end{tabular}

\section{Conclusões}

Nas condições deste estudo, o fornecimento do ovo desidratado não atenua o efeito negativo do ambiente com cama reciclada sobre o desempenho de pintainhas durante a primeira semana, mas pode melhorar o desempenho de aves alojadas em ambiente convencional. As pintainhas semipesadas são menos tolerantes que as leves aos ambientes contaminados, o que, possivelmente, está relacionado à atrofia do baço e da bolsa de Fabricius (tecidos linfóides).

\section{Literatura Citada}

ANDERSON, D.B.; MCCRACKEN, V.J.; AMINOV, R.L. et al. Gut microbiology and growth-promoting antibiotics in swine. Nutrition Abstracts and Reviews, v.70, p.101-108, 2000.

AVICULTURA INDUSTRIAL. Voltando a respirar. n.11, p.4247, 2003.

BAR-SHIRA, E.; SKLAN, D.; FRIEDMAN, A. Establishment of immune competence in the avian GALT during the immediate post-hatch period. Development and Comparative Immunology, v.27, p.147-157, 2003.

BIRKETT, S.; DE LANGE, K. A computational framework for a nutrient flow representation of energy utilization by growing monogastric animals. British Journal of Nutrition, v.86, p.661-674, 2001.

CALNEK, B.W.; BARNES, H.J.; BEARD, C.W. et al. Disease of poultry. 9.ed. Iowa: Iowa State University, 1991. 929p.

COATES, M.E.; FULLER, R.; HARRINSON, G.F. et al. A comparison of the growth of chicks in the Gustafsson germ-free apparatus and in a conventional environment, with and without dietary supplements of penicillin. British Journal Nutrition, v.17, p.141-151, 1963.

COOK, M.E. Antibodies: alternatives to antibiotic in improving growth in improving growth and feed efficiency. Journal Applied Poultry Research, v.13, p.103-119, 2004.

DAVISON, T.F. The immunologistics'debt to the chicken. British Poultry Science, v.44, p.6-21, 2005.

DIBNER, J.J. Early development of the digestive tract and the nutritional implications. Poultry Digest, p.16-19, 1997.

ERF, G.F.; TAYLOR, R.L. Ancillary scientists symposium: the avian immune system: function and modulation. Poultry Science, v.83, p.550-551, 2004.

ELWINGER, K.; ENGSTROM, B.; BERNDTSON, E. et al. Effect of protein level and feed enzyme addition on the caecal growth of $C$. perfringens in broiler chickens. In: WORLD POULTRY SCIENCE EUROPEAN POULTRY CONFERENCE, 9., 1994, Glasgow. Proceedings... Glasgow: WPS, 1994. p. 423-424.

EUCLYDES, R.F. Sistema de análises estatísticas e genéticas - SAEG. Viçosa, MG: Universidade Federal de Viçosa, 1983.

FULTON, J.E. Selection for avian immune response: a commercial breeding company challenge. Poultry Science, v.83, p.658$661,2004$.

GUYTON, A.C.; HALL, J.E. Tratado de fisiologia médica. Rio de Janeiro: Guanabara Koogan, 1997. 1008p.

HANNAS, M.I.; KRONKA, R.N.; THOMÁZ, M.C. et al. Composição química, valores de energia e proteína digestíveis do plasma suíno e ovo desidratado por spray-dried para suínos. In: REUNIÃO ANUAL DA SOCIEDADE BRASILEIRA DE ZOOTECNIA, 38., 2001, Piracicaba. Anais... Piracicaba: Sociedade Brasileira de Zootecnia, 2001. p.851-852.

HARMON, B.G.; LATOUR, M.A.; NORBERG, S. The use of spray dried eggs as an ingredient in diets for infantile pigs and broilers Swine Research Report, Purdue University, 2001. p.72. Disponível em: http:<www.ansc.purdue.edu/swine/swineday/ sday02/5.pdf.> Acesso em: 15/03/2004.

HARMON, B.G.; LATOUR, M.A.; NORBERG, S. Sprayed dried eggs as a source of immune globulins for SEW pigs. Swine Research Report, Purdue University. p.31-35, 2002. Disponível em: http:<www.ansc.purdue.edu/swine/swineday/sday02/5.pdf. > Acesso em: 15/03/ 2004. 
HARMS, H.C.; SIMPSON, C.F.; DARNRON, B.L. et al. Influence of chronic intestinal coccidiosis on protein requirements of laying hens. Poultry Science, v.46, p.192-194, 1967.

LEVS, M.; FORBES, M. Growth response to dietary penicillin of germ-free chicks with a defined intestinal flora. British Journal of Nutrition, v.13, p.78-84, 1959.

LILLEHOJ, H.S.; MIN, W.; DALLOUL, R.A. Recent progress on the cytokine regulation of intestinal immune response to Eimeria. Poultry Science, v.83, p.611-623, 2004.

NOY, Y.; GEYRA, A.; SKLAN, D. The effect of early feeding on growth and small intestinal development in the post hatch poultry. Poultry Science, v.80, p.912-919, 2001.

NOY, Y.; SKLAN, D. Energy utilization in newly hatched chicks. Poultry Science, v.78, p.1750-1756, 1999.

OWUSU-ASIEDU, A.; NYACHOTI, C.M.; MARQUARDT, R.R. Response of early-weaned pigs to an enterotoxigenic Escherichia coli (K88) challenge when fed diets containing spray-dried porcine plasma or pea protein isolate plus egg yolk antibody, zing oxide, fumaric acid, or antibiotic. Journal of Animal Science, v.81, p.1790-1798, 2003a.

OWUSU-ASIEDU, A.; NYACHOTI, C.M.; BAIDOO, S.K. et al. Response of early-weaned pigs to na enterotoxigenic Escherichia coli (K88) challenge when fed diets containing spray-dried porcine plasma or pea protein isolate plus egg yolk antibody. Journal of Animal Science, v.81, p.1781-1789, 2003b.

PERSIA, M.E.; YOUNG, E.L.; UTTERBACK, P.L. et al. Effect of dietary ingredients and Eimeria acervulina infection chick performance, apparent metabolizable energy, and amino acid digestibility. Poultry science, v.85, p.48-55, 2006.

ROSTAGNO, H.S.; ALBINO, L.F.T.; DONZELE, J.L. et al. Tabelas brasileiras para suínos e aves: composição de alimentos e exigências nutricionais. Viçosa, MG: Universidade Federal de Viçosa, 2000. 141p.
ROURA, E.; HOMENDES, J.; KLASSING K. Prevention of immunologic stress contributes to the growth-permitting ability of dietary antibiotic in chicks. Journal of Nutrition, v.122, p.2383-2390, 1992.

SCHIMIDT, L.S.; NYACHOTI, C.M.; SLOMINSKI, B.A. Nutritional evaluation of egg byproducts in diets for early-weaned pigs. Journal of Animal Science, v.81, p.2270-2278, 2003.

SCHUTTE, J.B.; DE JONG, J.; HOLSHEIMER, J.P. et al. Protein/ amino acid requirements of broiler chickens during the periods 0-2, 2-4 and 4-6 weeks of age. Wageningen: ILOB/ COVP-Rapport, 1993. 192p.

STADELMAN, W.J.; COTTERILL, O.J. Egg science and technology. 4.ed. New York: Food Products Press, 1995. 591p.

ST ANLEY, V.G; GRAY, C.; DALEY, M. et al. An alternative to antibiotic-based drugs in feed for enhancing performance of broilers grown on Eimeria spp.-infected litter. Poultry Science, v.83, p.39-44, 2004.

TEIXEIRA, E.N.M.; SILVA, J.H.V.; BARROS, I.R. et al. Valor nutritivo do ovo desidratado e do caldo de cana para pintos. Revista Brasileira de Ciência Avícola, v.7, p.130, 2005.

Van der WAAIJ, E.H.; BIJMA, P.; BISHOP, S.C. et al. Modeling selection for production traits under constant infection pressure. Journal of Animal Science, v.78, p.2809-2820, 2000.

WILLIS, G.M.; BAKER, D.H. Interaction between dietary protein/ amino acid level and parasitic infection: morbidity in amino acid deficient or adequate chicks inoculated with Eimeria acervulina. Journal of Nutrition, v.111, p.1157-1163, 1981. 